\title{
Doação de órgãos e tecidos na perspectiva de alunos oriundos de escola pública
}

\author{
Stefanie Goulart*, Ana Raquel Medeiros Beck
}

\section{Resumo}

Introdução: No ano de 2015 ocorreu queda de $8 \%$ no número de transplantes de órgãos sólidos em crianças no Brasil ${ }^{1}$ e a recusa familiar representa a principal causa da diminuição de taxa de doação de órgãos². Objetivos: Avaliar os conhecimentos dos alunos do ProFIS (Programa de Formação Interdisciplinar Superior), oriundos de escola pública, sobre doação de órgãos em crianças e adolescentes. Método: Trata-se de um estudo quantitativo, descritivo e transversal. Os alunos receberão por e-mail um questionário elaborado na plataforma SurveyMonkey, que será respondido no segundo semestre do ano de 2016, sobre questões de opinião e percepção sobre o transplante de órgãos e tecidos em crianças e adolescentes.

\section{Palavras-chave: \\ Obtenção de Tecidos e Órgãos, transplante, Educação em Enfermagem}

\section{Introdução}

Constatou-se que no ano de 2015 houve queda de $8 \%$ no número de transplantes de órgãos sólidos em crianças no Brasil ${ }^{1}$ e que a recusa familiar representa $44 \%$ das causas da não concretização da doação de órgãos de potenciais doadores notificados nos estados brasileiros, seguida da contra indicação médica com $17 \%$ dos casos, entre janeiro e março de $2016^{2}$. Dentre as causas de recusa familiar, estão a não compreensão do diagnóstico de Morte Encefálica (ME) por familiares, aspectos relacionados à religião e ao despreparo do profissional ao realizar a entrevista com a família do potencial doador ${ }^{3}$. A constatação do estado clínico de ME deve ter conhecimento e causa bem esclarecidos, além de ser obrigatória sua notificação, conforme determina a lei vigente, e é necessário a identificação de um potencial doador para o processo de manutenção dos órgãos, bem como seu diagnóstico: "Morte Encefálica, é definida como a parada completa e irreversível de todas as funções encefálicas, tanto dos hemisférios cerebrais quanto do tronco cerebral", ou seja, a interrupção definitiva de todas as atividades cerebrais, conceito definido pela resolução CFM $n^{\circ} 1.480 / 97$, Termo de Declaração de Morte Encefálica no Brasil do Conselho Federal de Medicina de $1997^{4}$. Tendo em vista estes pressupostos a pesquisa visa avaliar o conhecimento sobre doação de órgãos entre alunos oriundos do Ensino Médio de escola pública do ProFIS, Programa de Formação Interdisciplinar Superior, curso oferecido desde o ano de 2011 pela Universidade Estadual de Campinas (Unicamp) ${ }^{5}$, modalidade de ação afirmativa e inclusão social.

\section{Objetivo}

Avaliar os conhecimentos dos alunos do ProFIS sobre o panorama atual brasileiro de doação de órgãos de crianças e adolescentes e analisar se seus conhecimentos e opiniões sobre o tema sofreram interferências com a formação recebida no decorrer do curso.

\section{Metodologia}

Foi desenvolvido um questionário, a partir da plataforma SurveyMonkey, que será respondido no segundo semestre deste ano por cerca de 200 alunos do ProFIS (Programa de Formação Interdisciplinar Superior), ingressos dos anos 2015 e 2016, e que abordará questões de opinião e conhecimento sobre o transplante de órgãos e tecidos em crianças e adolescentes.

\section{Agradecimentos}

Agradeço a Bolsa SAE/ProFIS, ao PIBIC/CNPQ e a minha orientadora Profa. Dra. Ana Raquel Medeiros Beck, por todo o apoio e disposição para comigo durante todo o desenvolvimento do trabalho.

\footnotetext{
Referências:

1.Registro Brasileiro de Transplantes (RBT). Dimensionamento dos transplantes no Brasil em cada Estado (2008-2015). Ano XXI, no4, 2015.

${ }^{2}$.Registro Brasileiro de Transplantes (RBT). Dados Numéricos da doação de órgãos e transplantes realizados por estado e instituição no período: JANEIRO/MARÇO-2016. Ano XXI, no1, 2016.

3.Pessoa J L H., Schirmer J,; Roza B. de A. Avaliação das causas de recusa familiar a doação de órgãos e tecidos. Acta paul. enferm. [online]. 2013, vol. 26, n.4, pp.323-330. ISSN 1982-0194.

4.Domingos G R, Boer LA., Possamai F P. Doação e captação de órgãos de pacientes com morte encefálica. Enferm Brasil. 2010; 9(4):206-12.

5.PRÓ-REITORIA DE GRADUAÇÃO. Universidade Estadual de Campinas. Projeto Pedagógico: Programa de Formação Interdisciplinar Superior. 2010.
} 